\title{
PENGARUH KESADARAN WAJIB PAJAK DAN KUALITAS PELAYANAN FISKUS TERHADAP KEPATUHAN WAJIB PAJAK ORANG PRIBADI PADA KANTOR PELAYANAN PAJAK PRATAMA MALANG SELATAN
}

\author{
Yessica Tanilasari ${ }^{1}$ dan Pujo Gunarso ${ }^{2}$ \\ ${ }^{1,2}$ Universitas Merdeka Malang \\ ${ }^{1}$ Yessicatan07@gmail.com \\ ${ }^{2}$ Pujo.lelly@gmail.com
}

\begin{abstract}
This research aimed to analyze the influence of tax payers awareness and the quality service tax authorities on individual tax compliance. This research was conducted on Kantor Pelayanan Pajak Pratama Malang Selatan. The population in this research was a non employees individual tax payers of Kantor Pelayanan Pajak Pratama Malang Selatan. Samples were taken by convenience sampling method, with a total sample of 100 respondents. Methods of data collection carried out using questionnaires. This research using validity and reliability test, and multiple linear regression analysis. The analysis showed that the taxpayer Awareness positive effect on compliance of individual taxpayers. This meant that the higher the level of awareness taxpayer individual taxpayer compliance will also increase. Quality of service fiscus positive effect on compliance of individual tax payers. This meant that the quality of service that increases the tax authorities, the compliance of individual taxpayers also will increase. Awareness of tax payers and service quality fiscus positive effect on compliance of individual taxpayers. This meant that an individual tax payer compliance can be achieved with the existence of two variables: the awareness of tax payers and the quality of service tax authorities.
\end{abstract}

Keywords : tax payers awareness, quality service tax authorities, individual tax compliance

\section{PENDAHULUAN}

Pajak merupakan sumber pendapatan negara yang mempunyai potensi besar dalam mendukung program kerja pemerintahan dalam melakukan perubahan sehingga tujuan pemerintah dapat tercapai. Namun upaya meningkatkan penerimaan negara dari sektor pajak mempunyai banyak kendala diantaranya tingkat kepatuhan wajib pajak yang masih rendah sehingga wajib pajak berusaha untuk membayarkan pajaknya lebih kecil daripada seharusnya dan juga masih banyak wajib pajak yang belum melaporkan dan membayar pajak.

Direktorat jendral pajak telah menempuh berbagai cara untuk meningkatkan kepatuhan wajib pajak diantaranya mulai dari sosialisasi, pendekatan persuasif, jemput bola, pelayanan yang lebih baik, penegakan hukum, mengajak tokoh-tokoh bangsa dan masyarakat untuk menjadi panutan, hingga pengadaan tax amnesty. Namun upaya ini berjalan kurang maksimal. Tax ratio di Indonesia masih sangat kecil dan tidak sebanding dengan jumlah penduduk Indonesia. Tax ratio ini merupakan rasio jumlah wajib pajak terhadap jumlah penduduk di Indonesia. Berdasarkan data tahun 2014, jumlah penduduk Indonesia yang memiliki penghasilan di atas penghasilan tidak kena pajak (PTKP) sebanyak 44,8 juta orang. Namun demikian, baru 26,8 juta orang di antaranya yang telah terdaftar sebagai wajib pajak. Dari jumlah tersebut, hanya 10,3 juta wajib pajak yang menyampaikan SPT. Hal serupa juga terjadi dengan wajib pajak badan. Dari 1,2 juta perusahaan yang terdaftar sebagai wajib pajak badan, hanya sekitar 45,8 persen 
atau 550 ribu perusahaan yang menyampaikan SPT (Kemenkeu, 2015).

Kepatuhan wajib pajak dapat meningkatkan pendapatan negara. Penghindaran pajak yang mengakibatkan berkurangnya pendapatan negara dari sektor pajak. Bila ingin memaksimalkan penerimaan pajak, maka pemerintah harus berupaya agar wajib pajak semakin sadar bahwa peranan pajak sangatlah penting bagi tercapainya pembangunan nasional. Pelayanan yang diberikan oleh fiskus juga penting mengingat wajib pajak membutuhkan kenyamanan dalam membayar pajak.

\section{KAJIAN PUSTAKA DAN \\ PENGEMBANGAN HIPOTESIS}

Pajak adalah iuran rakyat kepada kas negara berdasarkan undang-undang (yang dapat dipaksakan) dengan tidak mendapat jasa timbal balik (kontraprestasi) yang langsung dapat ditunjukkan, dan digunakan untuk membiayai pengeluaran umum negara (Sasmita, 2015).

Menurut Peraturan Menteri Keuangan nomor 119/PMK.08/2016 Wajib pajak adalah orang pribadi atau badan yang mempunyai hak dan kewajiban perpajakan sesuai dengan ketentuan peraturan perundang-undangan di bidang perpajakan.

Kepatuhan secara umum dapat diartikan sebagai tindakan untuk mengikuti suatu ajaran tertentu dimana terdapat tuntutan untuk taat. Kepatuhan wajib pajak adalah suatu ketaatan untuk memenuhi ketentuan-ketentuan atau aturan-aturan perpajakan yang diwajibkan atau diharuskan untuk dilaksanakan (Noviyanti, et al, 2016).

Kesadaran wajib pajak adalah suatu kondisi dimana wajib pajak mengetahui, mengakui, menghargai dan menaati ketentuan perpajakan yang berlaku serta memiliki kesungguhan dan keinginan untuk memenuhi kewajiban pajaknya (Wilda, 2015). Kesadaran secara umum berarti suatu keadaan tahu, mengerti, dan merasa untuk mematuhi ketentuan yang berlaku menyangkut ketentuan tersebut telah diketahui, diakui, dihargai, dan ditaati.

Pelayanan merupakan cara untuk membantu mengurus atau menyiapkan suatu keperluan yang dibutuhkan sedangkan fiskus adalah petugas pajak. Pelayanan fiskus dapat diartikan sebagai cara petugas pajak dalam membantu mengurus atau menyiapkan segala keperluan yang dibutuhkan seseorang dalam hal ini adalah wajib pajak (Jatmiko, 2006).

Kerangka teoritis sebagai berikut:

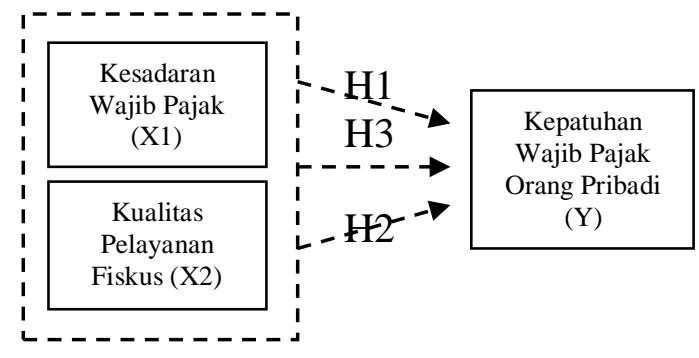

Gambar 1. Kerangka Teoritis

Menurut penelitian Permatasari (2014) menyatakan bahwa kesadaran wajib pajak berpengaruh signifikan terhadap kepatuhan wajib pajak orang pribadi yang melakukan kegiatan usaha dan pekerjaan bebas di KPP 
Pratama Surakarta. Dari pernyataan tersebut maka hipotesis pertama penelitian ini adalah:

H1: Kesadaran wajib pajak berpengaruh positif terhadap kepatuhan wajib pajak orang pribadi.

Menurut penelitian yang dilakukan oleh Sasmita (2015) menyatakan bahwa pelayanan fiskus berpengaruh positif terhadap kepatuhan wajib pajak. Peningkatan kualitas pelayanan akan meingkatkan pula kepatuhan wajib pajak badan dalam membayar dan menyampaikan SPT. Dari pernyataan tersebut maka hipotesis kedua penelitian ini adalah:

$\mathrm{H} 2$ : Kualitas pelayanan fiskus berpengaruh positif terhadap kepatuhan wajib pajak orang pribadi.

Menurut penelitian yang dilakukan oleh Nurhakim dan Pratomo (2015) menyatakan bahwa pemahaman wajib pajak badan dan kualitas pelayanan berpengaruh positif terhadap kepatuhan wajib pajak badan. Dari pernyataan tersebut maka hipotesis ketiga penelitian ini adalah:

H3: Kesadaran wajib pajak dan kualitas
pelayanan fiskus berpengaruh positif
terhadap kepatuhan wajib pajak orang
pribadi.

\section{METODE PENELITIAN}

Variabel terikat pada penelitian ini adalah kepatuhan wajib pajak orang pribadi. Variabel bebas pada penelitian ini adalah kesadaran wajib pajak dan kualitas pelayanan fiskus. Pengukuran variabel terikat dan variabel bebas menggunakan skala likert 1 sampai 5 poin dimana nilai 1 memiliki arti sangat tidak setuju hingga 5 yang memiliki arti sangat setuju. Ruang lingkup penelitian ini adalah perpajakan yang meliputi kesadaran wajib pajak dan kualitas pelayanan fiskus terhadap kepatuhan wajib pajak orang pribadi. Penelitian ini dilakukan pada Kantor Pelayanan Pajak Pratama Malang Selatan yang berlokasi di jalan Merdeka Utara No. 3, Kiduldalem, Klojen, Malang. Populasi dalam penelitian ini adalah wajib pajak orang pribadi non karyawan yang terdaftar di Kantor Pelayanan Pajak Pratama Malang Selatan. Sampel penelitian yang digunakan diambil dari sebagian wajib pajak orang pribadi non karyawan. Pengambilan sampel dalam penelitian ini dilakukan dengan menggunakan non probability sampling dengan metode convenience sampling. Untuk menghitung jumlah sampel yang akan digunakan, maka menggunakan rumus slovin sebagai berikut:

$$
n=\frac{N}{1+N(e)^{2}}
$$

\section{Keterangan:}

n: ukuran sampel

$\mathrm{N}$ : jumlah populasi

e: persentase kesalahan yang ditolerir dalam pengambilan sampel, pada penelitian ini menggunakan $\mathrm{e}=10 \%(0,1)$

Dalam penelitian ini didapat populasi wajib pajak orang pribadi non karyawan sebesar 20.569 dan sampel yang digunakan dalam penelitian ini berdasarkan perhitungan slovin adalah sebesar 100 sampel. Sumber data yang diperlukan dalam penelitian ini adalah data primer dan data sekunder. Data primer yaitu 
data yang berasal langsung dari para wajib pajak orang pribadi yang terdaftar di Kantor Pelayanan Pajak Pratama Malang Selatan. Data ini berupa kuesioner yang telah diisi oleh wajib pajak yang menjadi responden terpilih dalam penelitian ini. Data sekunder yaitu data yang diperoleh dari laporan yang dibuat oleh Kantor Pelayanan Pajak Pratama Malang Selatan. Data tersebut berupa gambaran umum Kantor Pelayanan Pajak Pratama Malang Selatan serta data mengenai jumlah wajib pajak orang pribadi yang terdaftar dan yang menyampaikan SPT di Kantor Pelayanan Pajak Pratama Malang Selatan. Teknik pengumpulan data menggunakan field study dengan menyebar kuesioner. Teknik analisis data yang digunakan dalam penelitian ini adalah uji validitas dan reliabilitas, uji asumsi klasik, analisis statistik deskriptif, dan analisis regresi linear berganda.

\section{HASIL DAN PEMBAHASAN}

\section{Uji Validitas dan Reliabilitas Data}

Apabila nilai $\mathrm{r}$ hitung $>\mathrm{r}$ tabel maka kuesioner dikatakan valid. Pada penelitian ini, $r$ tabel diperoleh dengan derajat kebebasan (N-2) atau $100-2=98$. Dengan pengujian 1 sisi (signifikansi $=0,05)$ diperoleh hasil $\mathrm{r}$ tabel sebesar 0,165 .

Tabel 1. Uji Validitas

\begin{tabular}{|c|c|c|c|c|c|}
\hline Variabel & Item & $\begin{array}{c}\text { Sig. (1- } \\
\text { tailed) }\end{array}$ & R hitung & R tabel & Keterangan \\
\hline \multirow{4}{*}{$\begin{array}{c}\text { Kesadaran } \\
\text { Wajib Pajak } \\
\text { (X1) }\end{array}$} & 1 & 0.000 & 0.460 & 0.165 & Valid \\
\cline { 2 - 6 } & 2 & 0.000 & 0.641 & 0.165 & Valid \\
\cline { 2 - 6 } & 4 & 0.000 & 0.593 & 0.165 & Valid \\
\cline { 2 - 6 } & 5 & 0.000 & 0.513 & 0.165 & Valid \\
\cline { 2 - 6 } & 7 & 0.000 & 0.555 & 0.165 & Valid \\
\cline { 2 - 6 } & 7 & 0.000 & 0.652 & 0.165 & Valid \\
\hline
\end{tabular}

\begin{tabular}{|c|c|c|c|c|c|}
\hline & 8 & 0.000 & 0.598 & 0.165 & Valid \\
\cline { 2 - 6 } & 9 & 0.000 & 0.497 & 0.165 & Valid \\
\cline { 2 - 6 } & 10 & 0.000 & 0.376 & 0.165 & Valid \\
\hline \multirow{4}{*}{$\begin{array}{c}\text { Kualitas } \\
\text { Pelayanan }\end{array}$} & 11 & 0.000 & 0.632 & 0.165 & Valid \\
\cline { 2 - 6 } Fiskus (X2) & 12 & 0.000 & 0.734 & 0.165 & Valid \\
\cline { 2 - 6 } & 13 & 0.000 & 0.624 & 0.165 & Valid \\
\cline { 2 - 6 } & 14 & 0.000 & 0.605 & 0.165 & Valid \\
\cline { 2 - 6 } & 15 & 0.000 & 0.563 & 0.165 & Valid \\
\hline \multirow{4}{*}{$\begin{array}{c}\text { Kepatuhan } \\
\text { Wajib Pajak } \\
\text { (Y) }\end{array}$} & 16 & 0.005 & 0.260 & 0.165 & Valid \\
\cline { 2 - 6 } & 18 & 0.000 & 0.552 & 0.165 & Valid \\
\cline { 2 - 6 } & 19 & 0.000 & 0.422 & 0.165 & Valid \\
\cline { 2 - 6 } & 21 & 0.000 & 0.569 & 0.165 & Valid \\
\cline { 2 - 6 } & 22 & 0.000 & 0.438 & 0.165 & Valid \\
\hline
\end{tabular}

Sumber : data diolah

Berdasarkan tabel diatas diketahui bahwa seluruh item dikatakan valid.

Tabel 2. Uji Reliabilitas untuk Kesadaran Wajib Pajak

\section{Reliability Statistics}

\begin{tabular}{|r|r|}
\hline Cronbach's Alpha & N of Items \\
\hline .794 & 10 \\
\hline
\end{tabular}

Sumber : data diolah

Berdasarkan tabel diatas diketahui nilai cronbach's alpha 0,794 > 0,6 sehingga variabel kesadaran wajib pajak adalah reliabel.

Tabel 3. Uji Reliabilitas untuk Kualitas Pelayanan Fiskus

\section{Reliability Statistics}

\begin{tabular}{|r|r|}
\hline Cronbach's Alpha & N of Items \\
\hline .798 & 6 \\
\hline
\end{tabular}

Sumber : data diolah

Berdasarkan tabel diatas diketahui nilai cronbach's alpha 0,798>0,6 sehingga variabel kualitas pelayanan fiskus adalah reliabel.

Tabel 4. Uji Reliabilitas Kepatuhan Wajib Pajak Reliability Statistics

\begin{tabular}{|l|l|}
\hline Cronbach's Alpha & N of Items \\
\hline
\end{tabular}




\section{Reliability Statistics}

\begin{tabular}{|r|r|}
\hline Cronbach's Alpha & N of Items \\
\hline .795 & 6 \\
\hline
\end{tabular}

Sumber : data diolah

Berdasarkan tabel diatas diketahui nilai cronbach's alpha 0,795 > 0,6 sehingga variabel kepatuhan wajib pajak adalah reliabel.

\section{Uji Asumsi Klasik}

Tabel 5. Hasil Uji Asumsi Klasik

\begin{tabular}{|l|c|c|c|c|}
\hline \multirow{2}{*}{ Variabel } & \multirow{2}{*}{$\begin{array}{c}\text { Norm } \\
\text { alitas }\end{array}$} & $\begin{array}{c}\text { Heterosked } \\
\text { astisitas }\end{array}$ & \multicolumn{2}{|c|}{ Multikolinearitas } \\
\cline { 3 - 5 } & & 0,092 & 0,630 & 1,58 \\
\hline $\begin{array}{l}\text { Kesadaran } \\
\text { Wajib Pajak }\end{array}$ & \multirow{2}{*}{0,268} & 0,393 & 0,630 & 1,58 \\
\cline { 1 - 3 } $\begin{array}{l}\text { Kualitas } \\
\text { Pelayanan } \\
\text { Fiskus }\end{array}$ & & & & 7 \\
\hline
\end{tabular}

Dependen Variabel: Kepatuhan Wajib Pajak Orang Pribadi Sumber : data diolah

Berdasarkan tabel diatas diketahui hasil pengujia asumsi klasik, dimana hasil pengujian menunjukkan data terdistribusi secara normal karena hasil pengujian sebesar 0,268>0,05. Pengujian heteroskedastisitas menunjukkan nilai sig. masing-masing variabel sebesar 0,092 > 0,05 dan $0,393>0,05$ yang berarti model regresi tidak mengandung adanya Heteroskedastisitas. Pada pengujian Multikolinearitas diketahui nilai tolerance masing-masing variabel $0,630>0,1$ dan nilai VIF $1,587<10$ sehingga model regresi tidak terjadi multikolinearitas.

\section{Analisis Statistik Deskriptif}

Tabel 6. Statistik Deskriptif

\begin{tabular}{|c|c|c|c|c|c|}
\hline Variabel & $\mathrm{N}$ & Min & Max & Mean & $\begin{array}{c}\text { Std. } \\
\text { Deviation }\end{array}$ \\
\hline $\mathrm{X} 1$ & 100 & 1 & 5 & 3,86 & 0,551 \\
\hline $\mathrm{X} 2$ & 100 & 2 & 5 & 3,94 & 0,633 \\
\hline $\mathrm{Y}$ & 100 & 3 & 5 & 3,97 & 0,437 \\
\hline
\end{tabular}

Sumber : data diolah
Berdasarkan tabel diatas diketahui variabel kesadaran wajib pajak memiliki nilai rata-rata 3,86 hal ini menunjukkan bahwa sebagian besar responden cenderung menjawab setuju dengan nilai minimum 1 dan nilai maksimum 5. Variabel kualitas pelayanan fiskus memiliki rata-rata 3,94 hal ini menunjukkan bahwa sebagian besar responden cenderung menjawab setuju dengan nilai minimum 2 dan nilai maksimum 5. Variabel kepatuhan wajib pajak orang pribadi memiliki rata-rata 3,97 hal ini menunjukkan bahwa sebagian besar responden cenderung menjawab setuju dengan nilai minimum 3 dan nilai maksimum 5.

\section{Analisis Regresi Linear Berganda}

Tabel 7. Hasil Analisis Regresi Linear Berganda

\begin{tabular}{|l|c|c|}
\hline Variabel & Koefisien Regresi & Sig. \\
\hline $\begin{array}{l}\text { Kesadaran Wajib } \\
\text { Pajak }\end{array}$ & 0,292 & 0,010 \\
\cline { 1 - 1 } $\begin{array}{l}\text { Kualitas Pelayanan } \\
\text { Fiskus }\end{array}$ & 0,266 & 0,018 \\
\cline { 1 - 1 } Konstanta : 13,32 & \\
\cline { 1 - 1 } F $: 16,235$ & $\mathrm{Y}=13,32+0,292 \mathrm{X} 1+0,266 \mathrm{X} 2+\mathrm{e}$ \\
\cline { 1 - 2 } $\begin{array}{l}\text { Adjusted R Square : } \\
0,235\end{array}$ & \\
\hline
\end{tabular}

Sumber : data diolah

Berdasarkan tabel diatas, koefisien regresi variabel X1 (kesadaran wajib pajak) bernilai positif 0,292 artinya kesadaran wajib pajak berpengaruh positif terhadap kepatuhan wajib pajak orang pribadi. Koefisien regresi variabel X2 (kualitas pelayanan fiskus) bernilai positif 0,266 artinya kualitas pelayanan fiskus berpengaruh positif terhadap kepatuhan wajib pajak orang pribadi.

Variabel kesadaran wajib pajak (X1) memiliki nilai signifikansi 0,010 lebih kecil dari 0,05. Sehingga H1 diterima, yang artinya 
kesadaran wajib pajak secara parsial faktor yang menentukan tingkat kepatuhan berpengaruh terhadap kepatuhan wajib pajak. wajib pajak orang pribadi pada Kantor Hasil uji untuk variabel kualitas pelayanan Pelayanan Pajak Pratama Malang Selatan dalam fiskus (X2) memiliki nilai signifikansi 0,018 lebih kecil dari 0,05. Sehingga H2 diterima, yang artinya kualitas pelayanan fiskus secara parsial berpengaruh terhadap kepatuhan wajib pajak. Hasil pengujian menunjukkan bahwa $\mathrm{F}$ hitung > F tabel dan nilai signifikansinya lebih kecil dari 0,05. Sehingga hipotesis 3 diterima, yang artinya variabel kesadaran wajib pajak (X1), kualitas pelayanan fiskus (X2) berpengaruh secara simultan terhadap kepatuhan wajib pajak (Y). Koefisien determinasi (R2) sebesar 0,235 atau $23,5 \%$ hal ini menunjukkan bahwa persentase besarnya pengaruh kesadaran wajib pajak dan kualitas pelayanan fiskus terhadap kepatuhan wajib pajak orang pribadi adalah sebesar 23,5\%, sedangkan sisanya $76,5 \%$ dipengaruhi oleh variabel lain diluar penelitian.

Kesadaran wajib pajak mengenai perpajakan antara lain wajib pajak memahami sistem perpajakan yang digunakan (menghitung, membayar, dan melapor sendiri), mengetahui fungsi pajak sebagai sumber penerimaan negara yang digunakan untuk pembiayaan negara, serta memahami peraturan perpajakan mengenai pengisian SPT dan membayar kewajiban pajaknya. Sehingga semakin tinggi kesadaran wajib pajak akan semakin meningkatkan kepatuhan wajib pajak orang pribadi. Demikian kesadaran wajib pajak searah dengan tingkat kepatuhan wajib pajak orang pribadi. Sehingga kesadaran wajib pajak merupakan salah satu menjalankan kewajiban perpajakannya.

Pelayanan pajak berupa fasilitas fisik dan pelayanan dari petugas pajak yang baik dapat membuat tingkat kepatuhan wajib pajak meningkat. Adanya pelayanan yang didukung oleh fasilitas-fasilitas seperti tempat parkir yang luas, tempat nyaman dan bersih, tersedianya formulir-formulir pajak, tersedianya tempat bermain anak bila ada wajib pajak yang membawa anak, adanya nomor antrian elektronik, serta dukungan IT atau e-system. Selain tersedianya fasilitas fisik yang nyaman, pelayanan yang diberikan oleh fiskus sangat mendukung seperti petugas pajak yang ramah dan sopan, petugas pajak yang cepat tanggap dalam memberikan informasi dan solusi dalam membantu menyelesaikan persoalan yang dihadapi oleh wajib pajak, petugas pajak yang memberikan pelayanan terbaik dalam memberikan kemudahan dalam pelayanan pajak, serta petugas pajak yang dapat menjunjung tinggi integritas, akuntabilitas, dan transparansi dapat menimbulkan kepercayaan dari wajib pajak. Dengan adanya fasilitasfasilitas tersebut dapat dikatakan bahwa Kantor Pelayanan Pajak Pratama Malang Selatan telah memberikan pelayanan dengan baik, sehingga wajib pajak merasa puas dan akhirnya dapat meningkatkan kepatuhan wajib pajak orang pribadi dalam melaksanakan kewajibannya.

Kesadaran wajib pajak dan kualitas pelayanan fiskus merupakan faktor yang penting 
dalam meningkatkan kepatuhan wajib pajak orng pribadi. Kesadaran akan peraturan perpajakan yang baik akan memudahkan wajib pajak dalam memenuhi kewajibannya. Kualitas pelayanan fiskus yang baik dari instansi pajak dapat menjadi modal utama dan menjadi hal yang penting untuk dapat menarik perhatian dan menimbulkan kepercayaan wajib pajak. Dengan demikian semakin tinggi kesadaran wajib pajak dan kualitas pelayanan fiskus maka akan semakin tinggi pula tingkat kepatuhan wajib pajak orang pribadi.

\section{SIMPULAN DAN SARAN}

Berdasarkan hasil penelitian, maka dapat ditarik kesimpulan sebagai berikut:

1. Kesadaran wajib pajak berpengaruh positif terhadap kepatuhan wajib pajak orang pribadi. Hal ini memberikan makna bahwa semakin tinggi kesadaran wajib pajak maka tingkat kepatuhan wajib pajak orang pribadi juga akan meningkat, sebaliknya bila kesadaran wajib pajak rendah maka tingkat kepatuhan wajib pajak orang pribadi juga akan menurun.

2. Kualitas pelayanan fiskus berpengaruh positif terhadap kepatuhan wajib pajak orang pribadi. Hal ini memberikan makna bahwa kualitas pelayanan fiskus yang meningkat maka kepatuhan wajib pajak orang pribadi juga akan meningkat, begitu pula sebaliknya bila kualitas pelayanan fiskus rendah maka tingkat kepatuhan wajib pajak orang pribadi juga akan menurun.
3. Kesadaran wajib pajak dan kualitas pelayanan fiskus berpengaruh positif terhadap kepatuhan wajib pajak orang pribadi. Hal ini memberikan makna bahwa kepatuhan wajib pajak orang pribadi dapat dicapai dengan adanya kedua variabel yaitu kesadaran wajib pajak dan kualitas pelayanan fiskus. Bila kesadaran wajib pajak dan kualitas pelayanan fiskus baik maka tingkat kepatuhan wajib pajak orang pribadi pun akan baik, sebaliknya bila kesadaran wajib pajak dan kualitas pelayanan fiskus buruk maka tingkat kepatuhan wajib pajak orang pribadi akan menurun.

\section{Saran}

Berdasarkan kesimpulan diatas, maka saransaran yang dapat diberikan terkait kesadaran wajib pajak dan kualitas pelayanan fiskus terhadap kepatuhan wajib pajak orang pribadi adalah sebagai berikut:

1. Bagi Pemerintah

Pemerintah sebagai pembuat keputusan dan kebijakan diharapkan bisa memberikan kepastian hukum dan kejelasan atas kebijakan yang dikeluarkan khususnya tentang perpajakan sehingga warga negara akan semakin sadar akan pentingnya pajak dan menjadi patuh dalam menjalankan kewajiban pajaknya.

2. Bagi Instansi

Sebagai wakil dari pemerintah, instansi pajak diharapkan dapat lebih memperhatikan wajib pajak terutama wajib 
pajak yang belum melakukan kewajiban perpajakan sehingga wajib pajak tidak keberatan untuk membayar pajaknya.

3. Bagi Peneliti Selanjutnya

Bagi peneliti selanjutnya disarankan untuk menambah variabel bebas yang memiliki keterkaitannya dengan kesadaran wajib pajak dan kualitas pelayanan fiskus terhadap kepatuhan wajib pajak orang pribadi serta dapat menambah sampel penelitian.

\section{DAFTAR PUSTAKA}

Arikunto, Suharsimi. 2002. Prosedur Penelitian Suatu Pendekatan Praktek. Rineka Cipta: Yogyakarta

Herryanto, Marisa dan Agus Arianto Toly. 2013. Pengaruh Kesadaran Wajib Pajak, Kegiatan Sosialisasi Perpajakan, Dan Pemeriksaan Pajak Terhadap Penerimaan Pajak Penghasilan Di KPP Pratama Surabaya Sawahan. Tax \& Accounting Review. Vol 1. No 1

Jotopurnomo, Cindy dan Yenni Mangoting. 2013. Pengaruh Kesadaran Wajib Pajak, Kualitas Pelayanan Fiskus, Sanksi Perpajakan, Lingkungan Wajib Pajak Berada Terhadap Kepatuhan Wajib Pajak Orang Pribadi Di Surabaya. Tax \& Accounting Review. Vol 1. No 1

Jatmiko, Agus Nugroho. 2006. Pengaruh Sikap Wajib Pajak Pada Pelaksanaan Sanksi Denda, Pelayanan Fiskus Dan Kesadaran Perpajakan Terhadap Kepatuhan Wajib Pajak (Studi Empiri Terhadap Wajib Pajak Orang Pribadi Di Kota Semarang). Tesis - Program Studi Magister Akuntansi. Semarang: Universitas Diponegoro

Jatikom. 2016. Sistem Perpajakan Indonesia. http://www.jatikom.com/ 2016/08/sistemperpajakan-indonesia.html
Kundalini, Pertiwi. 2016. Pengaruh Kesadaran Wajib Pajak Dan Pelayanan Pegawai Pajak Terhadap Kepatuhan Wajib Pajak Pada Kantor Pelayanan Pajak Pratama Kabupaten Temanggung Tahun 2015. Skripsi - Program Studi Akuntansi. Yogyakarta: Universitas Negeri Yogyakarta

Kemenkeu. 2015. Pemerintah Canangkan Tahun Pembinaan Wajib Pajak 2015. http://www.kemenkeu.go.id/Berita/pemeri ntah-canangkan-tahun-pembinaan-wajibpajak-2015

Mardiasmo. 2009. Perpajakan. Penerbit Andi: Jakarta

Noviyanti, Siska, Rizal Effendi, dan Christina Yunita W. 2016. Pengaruh Kesadaran Wajib Pajak, Pengetahuan Dan Pemahaman Peraturan Perpajakan, Kualitas Pelayanan Dan Ketegasan Sanksi Perpajakan Terhadap Kepatuhan WPOP (Studi Kasus KPP Pratama Ilir Barat Palembang). STIE MDP

Nurhakim, Tifani dan Dudi Pratomo. 2015. Pengaruh Pemahaman Wajib Pajak Dan Kualitas Pelayanan Terhadap Kepatuhan Wajib Pajak Badan (Studi Pada Kantor Pelayanan Pajak Pratama Tasikmalaya). E-Proceeding of Management. Vol 2. No 3

Pajak, Online. 2015. Wajib Pajak Orang Pribadi. http://www.onlinepajak.com/id/wajib-pajak-orang-pribadi

Permatasari, MSY Rizka. 2014. Pengaruh Kesadaran Wajib Pajak, Pelayanan Fiskus, Pengetahuan Pajak Dan Sanksi Pajak Terhadap Kepatuhan Wajib Pajak Orang Pribadi Yang Melakukan Kegiatan Usaha Dan Pekerjaan Bebas (Studi Kasus Pada KPP Kartasura). Skripsi - Fakultas Ekonomi. Surakarta: Universitas Muhammadiyah

Sasmita, Sentya N Arum. 2015. Pengaruh Pemahaman Wajib Pajak, Pelayanan Fiskus, Kesadaran Wajib Pajak Dan Sanksi Perpajakan Terhadap Kepatuhan 
Wajib Pajak Pemilik Usaha Kecil Menengah Dalam Pelaporan Kewajiban Perpajakan Di Semarang (Studi UMKM Di Kota Semarang). Journal of Accounting. Vol 1. No 1

Sugiyono. 2007. Statistika untuk Penelitiana. Alfabeta: Bandung

Utomo, Dwiarso, Setiwanta, Yulita dan Yulianto Agung. 2011. Perpajakan Aplikasi \& Terapannya. Penerbit Andi: Yogyakarta

Wilda, Fitri. 2015. Pengaruh Kesadaran Wajib Pajak, Pelayanan Fiskus Dan Sanksi Pajak Terhadap Kepatuhan WPOP Yang Melakukan Kegiatan Usaha Dan Pekerjaan Bebas Di Kota Padang. Skripsi - Fakultas Ekonomi. Padang: Universitas Negeri Padang 